\title{
Proposições nietzschianas para pensar a questão animal*
}

\author{
Mónica B. Cragnolini**
}

Resumo: No parágrafo 7 do livro I de $A$ gaia ciência, intitulado "Algo para homens trabalhadores", Nietzsche indica um "programa de trabalho" para a nova ciência alegre, programa que afasta a filosofia dos lugares habituais a que está habituada, pondo-a em relação com as condições históricas, culturais e fisiológicas. Do mesmo modo, fala-se em A gaia ciência de uma "história natural do animal", e dado o vínculo existente entre o nascimento da moral e nossa relação com os animais (tal como se indica em Humano, demasiado humano II, 57) considero que parte desse trabalho para laboriosos na época atual deve realizar-se em relação à questão animal. Delinearei, então, algumas proposições da filosofia nietzschiana para pensar esse tema, sobretudo desde a crítica e a denúncia daqueles prejuízos humanistas que seguem formando parte "naturalizada" de nosso vínculo com os animais.

Palavras-chave: Nietzsche, Animal Studies, sarcofagia, devoração.

* Tradução de Márcio José Silveira Lima.

** Professora da Universidade de Buenos Aires/CONICET, Buenos Aires, Argentina.

Correio eletrônico: mcragnolini@gmail.com 
Se, como poderíamos pensar, o trabalho filosófico de Foucault se encontra motivado pelo parágrafo 7 do livro I de $A$ gaia ciência, intitulado "Algo para homens trabalhadores", é a partir daí que seria possível pensar, também, uma série de tarefas para a interpretação da filosofia nietzschiana que não deseja reduzir-se à filologia, mas que adverte para a força desse pensar extemporâneo para o momento atual. De fato, Nietzsche nos exige, de alguma maneira, a pensar nosso presente e nossa condição histórica: a "filosofia do risco", do talvez [Vieleicht] é uma aposta para perguntarmos, aqui e agora, por aquilo que nos acontece. No parágrafo mencionado, Nietzsche formula um "programa de trabalho" para a nova ciência "jovial", e esse programa lhe indica tarefas como, por exemplo, rastrear e repensar as paixões em escala individual, social e histórica; fazer uma história do amor, da inveja, da crueldade, do direito e do castigo; escrever "uma filosofia da nutrição"; recopilar as experiências dos conventos, do matrimônio e da amizade, os costumes de distintos grupos professionais etc. Dessa lista de tarefas retomo a proposta de uma "filosofia da nutrição", unindo-a à "história natural do animal" (uma ideia que aparece em A gaia ciência), para afirmar que uma parte do trabalho que desde já se pode delinear para os genealogistas nietzschianos de hoje se vincula com essa história, e seus nexos com a sarcofagia. De fato, um capítulo fundamental de uma filosofia da nutrição deveria abordar a questão sarcofágica, ou seja, a ingestão de cadáveres e sua naturalização na cultura. Tal naturalização pressupõe um vínculo com os viventes animais não humanos que pode ser pensado a partir de certas premissas do ideal ascético encarnado na ciência que se estabelece como objetiva, como se indica em Assim falou Zaratustra, "cortar a vida" (Za/ZA, KSA 4.312)

Para estabelecer esses vínculos, partirei de certas premissas interpretativas do pensamento nietzschiano, indicando, desse modo, sobre quais bases conceituais é possível pensar a questão animal. Com "questão animal" me refiro ao modo com que os Animal Studies têm 
Cragnolini, M. B.

levado a filosofia a repensar os vínculos e limites entre os distintos modos do vivente.

\section{Proposições nietzschianas para pensar a questão animal}

Em primeiro lugar, é necessário partir de uma interpretação da "morte de Deus" como fim dos humanismos (e de toda forma possível de "super-humanismo"). A morte de Deus é também a morte do homem, e de todo conceito de homem que o coloque no lugar de dono e de senhor de todo o que é (ou seja, em uma posição árkhica, como nómos e télos do real). Para compreender isso, é necessário considerar que para Nietzsche o "sujeito", tal como o pensou a filosofia moderna, é uma "sombra" de Deus (e a filosofia do martelo trata de destruir Deus e todas as suas sombras).

Em segundo lugar, há que recordar o valor do "Es denkt"1 que Nietzsche estabelece quando, em Para além de bem e mal, critica a ideia do "Eu penso"2. Nessa obra se critica a ideia de sujeito, seja entendida à maneira racional do "Eu penso", seja entendida ao modo volitivo do "Eu quero" (JGB/BM 16, KSA 5.29). Isso é sumamente relevante para compreender por que Nietzsche não pode ser interpretado como um defensor da individualidade e do si mesmo, entendido agora a partir do querer, e tampouco o além do homem [Übermensch] pode ser pensado à maneira de um supersujeito volitivo. Por isso, o parágrafo seguinte ao dessa crítica, o 17, destaca o conhecido "Es denkt" (JGB/BM 17, KSA 5.31). Este "Es" destrona o sujeito do lugar em que se havia localizado desde a filosofia moderna, e potencializa a ação do corpo. Como se indica no parágrafo 19: "Nosso corpo, com efeito, é apenas uma estrutura social de muitas almas - L'effet c'est moi: ocorre aqui o que ocorre em toda

1 "Isso Pensa". Nota do tradutor.

2 Trabalho essa problemática em detalhe em Mónica B. Cragnolini, 2005a.

122 | Cad. Nietzsche, Guarulhos/Porto Seguro, v.39, n.1, p. 120-131, janeiro/abril, 2018. 
coletividade bem estruturada e feliz, na qual a classe governante se identifica com os êxitos da coletividade" (JGB/BM 19, KSA 5.33). Este "Es" de Para além de bem e mal é o corpo de Assim falava Zaratustra (Za/ZA, Dos desprezadores do corpo, KSA 4.39), aquele que está "por trás" do Ich [eu], do qual se apropria como instrumento, e que de forma provocativa Nietzsche denomina também Selbst [si mesmo]. O Selbst para a tradição metafísica é o aspecto mais puro do eu (a autoconsciência e a representação), embora aqui se indique que é o corpo, com o qual se destitui o eu [Ich] de seu habitual lugar de arkhé e de domínio.

Em terceiro lugar, e como terceira premissa para compreender o tema animal em Nietzsche, há que pensar em una interpretação da vontade de potência que supõe a crítica a toda ideia de conservação, e, portanto, de domínio 3 .

Em quarto lugar, então, o homem que não deve ser nem melhorado, nem conservado, deve dar lugar a esse "outro modo de ser" totalmente diferente do homem dos humanismos, que é o além do homem. Com esse pensamento é possível compreender a questão animal: quando Zaratustra, na quarta parte da obra, recebe os homens superiores, o trânsito pela animalidade se faz pregnante, e esses "desesperados" não o suportam, e por isso fogem ante o leão que ri e o bando de pombas (o "signo" do Übermensch) ${ }^{4}$.Esses "homens superiores" se mostram como "demasiado humanos" para fazer frente à questão animal, mas então fica claro, também, que o trânsito pela animalidade não implica um retorno a épocas prévias ao humanismo, porém algo diferente ${ }^{5}$.

3 Nesse sentido, considero que a vontade de potência "que domina" remete ao aspecto punitivo (e portanto conservador) dessa vontade, tanto quanto o aspecto desagregador é o que rompe com todas as formações de poder [Herrschaftgebilde] que se querem conservar demasiado (para dominar).

4 Desenvolvo esse tema com detalhe em Mónica B. Cragnolini, 2010.

5 Nesse sentido, a "festa do asno" poderia ser interpretada como um retorno a um suposto "originário" animal, daí o rechaço por parte de Zaratustra: não se trata de erigir, agora, o animal no lugar do fundamento divino perdido.

Cad. Nietzsche, Guarulhos/Porto Seguro, v.39, n.1, p. 120-131, janeiro/abril, 2018. 
Cragnolini, M. B.

E em quinto lugar, creio que é uma condição inevitável para pensar a questão animal interpretar Nietzsche como um autor que abordou a problemática da alteridade, nos modos da hospitalidade e da comunidade 6 . A relevância concedida à questão do "estranho" na ideia de hospitalidade, "estranho" que impede toda assimilação pelo si mesmo e pelo domínio, permite compreender o tema da alteridade $^{7}$, e, portanto, a questão animal.

\section{Nietzsche como referente dos Animal Studies}

Por que pensar em Nietzsche, então, como um autor avantla-lettre dos estudos críticos sobre o animal? São muitos os temas a indicar: para além da referência na II Consideração Extemporânea à questão do animal e do esquecimento, é relevante recordar que o termo "animal" [Tier, Vieh] é utilizado por Nietzsche em diversos sentidos. Se para os humanismos o homem é um "animal racional", as expressões nietzschianas para caracterizar o vivente humano como "animal doméstico", "animal civilizado", "animal esquecido", "animal não definido", "animal ao qual seja lícito fazer promessas", manifestam que os "limites" não são tão claros e que talvez entre homem e animal não há barreiras tão claras, mas sim mescla, confusão, tensão de proximidade e distanciamento.

Por outro lado, em Humano, demasiado humano II Nietzsche argumenta que se poderia estudar a gênese da moral a partir da maneira como o homem trata os animais (WS/AS 57, KSA 2.577). É nesse sentido que me interessa, portanto, vincular a questão sacrificial e sarcofágica (como tema de uma "filosofia da nutrição) com a problemática da "história dos animais". Essa vinculação supõe voltar a pensar a história da moral em termos de sacrifício da vida, e

6 Cf. Mónica B. Cragnolini, 2005b.

7 Nietzsche expõe a importância da noção de "estranho" na ideia de hospitalidade em Aurora, 319 (M/A 319, KSA 3.226).

124 Cad. Nietzsche, Guarulhos/Porto Seguro, v.39, n.1, p. 120-131, janeiro/abril, 2018. 
propor - arriscando e tremendo - outros modos de vinculação com o vivente a partir da ideia nietzschiana de que se ama a vida não por hábito de viver, mas por hábito de amar ${ }^{8}$.

\section{A gaia ciência e a tarefa para os genealogistas nietzschianos: sarcofagia e tratamento do animal}

Frente ao ideal ascético exacerbado na ciência que "fere" a vida", Nietzsche defende uma "ciência jovial", ciência que pode pensar outro modo de ser diferente do humano "sacrificador" ou "viviseccionador" da vida ${ }^{10}$. Quando o parágrafo 354 de $A$ gaia ciência afirma que "a fisiologia e a história dos animais" [Physiologie und Thiergeschichte]" se tornam necessárias para nos livrarmos do prejuízo da consciência, se defende que "a vida inteira seria possível sem que, por assim dizê-lo, se visse no espelho" (FW/GC 354, KSA 3.590). Aqui se revela, segundo meu entender, o caráter da consciência não só como prejuízo que funda o limite entre o humano e o animal, como também o narcisismo de toda postura humanista. Quando na mesma obra se afirma que "o homem, como toda criatura vivente, pensa continuamente mas não o sabe " (FW/GC 115, KSA 3.474), há uma defesa do "Es denkt" ("isso pensa") antes mencionado, e pondo em xeque esse narcisismo humano que quer olhar-se todo o tempo no espelho (espelho da consciência, da representação, mas também da exaltação de si sob a ideia de dominador da natureza).

8 Refiro-me aqui à "filosofia do risco nietzschiana" em conjunção com o tremor derridiano, que implica o respeito ao outro em sua fragilidade.

9 Refiro-me com amplitude a essa questão em M. B. Cragnolini, 2012a.

10 A ciência "séria", frente à jovial, é aquela que exerce o científico da quarta parte de Assim falava Zaratustra (aquele que estuda o cérebro da sanguessuga): esta última é a ciência exacerbada pelo ideal ascético que aproveita (e goza) essa autocontradição da vida, e, por causa desta, para conservar-se, deve negar-se a si mesma. A vida é, para essa ciência, o que deve ser ferido, cortado, vivisseccionado. A vida pode ser vivisseccionada se se pensa que o vivente não humano não sofre ou não sente (e a parte do vivente humano que se considera menos humana, o corpo, o animal). A vivissecção é o modelo por excelência para os estudos biológicos na época moderna, partindo do pressuposto de que o vital opera de maneira automática, por simples reação, e, portanto, "não sofre".

Cad. Nietzsche, Guarulhos/Porto Seguro, v.39, n.1, p. 120-131, janeiro/abril, 2018. 
Cragnolini, M. B.

Por isso, quando o parágrafo 115 aponta para os erros que permitiram a crença na ideia de "humanidade", afirma-se que o homem "em terceiro lugar, se sentia a si mesmo como uma falsa hierarquia com respeito aos animais e à natureza [in einer falschen Rangordnung zu Thier und Natur]" (FW/GC 115, KSA 3.474).

\section{Sarcofagia e devoração em uma filosofia da nutrição}

O lugar sempre citado do pensamento nietzschiano para os temas da filosofia da nutrição é o capítulo "Por que sou tão inteligente" de Ecce Homo. Ali, após expor os problemas que (segundo diz) nunca lhe interessaram, Nietzsche defende a importância da alimentação para a moral (seja em sentido crítico, seja em sentido afirmativo, isto é, como elemento para as forças, e a virtú - pensada em termos das forças) e explica por que o "espírito alemão é uma indigestão". Indica também que a dieta inglesa é "uma volta à natureza, ou seja, ao canibalismo" e destaca a importância do lugar e do clima para o metabolismo, e como se pensa em função da fisiologia intestinal ${ }^{11}$. $\mathrm{O}$ interessante desse tratamento do tema da alimentação é que reforça o que indicávamos acima sobre o vínculo entre moral e fisiologia.

Interessa-me, em virtude desse vínculo, indicar os nexos entre a sarcofagia e nossa relação com os animais. Tenho utilizado o termo "sarcofagia", sabendo que Nietzsche alude a ele apenas uma vez, e não em suas obras, mas em uma carta a Carl von Gersdorf de 28 de setembro de 1869, na qual ele afirma que, desde a leitura de sua última missiva, em que seu amigo lhe comentava a decisão de ser vegetariano, ele já não pertence aos “sarcofágicos”, e recorda uma cena anterior na qual ele mesmo tentava explicar-lhe as características dessa escolha alimentícia, paradoxalmente, frente a um prato de

11 Como indica ali: "Uma inércia intestinal, convertida em mau hábito, basta para fazer de um gênio alguém medíocre”, (EH/EH, Por que sou tão inteligente, KSA 6.282).

126 | Cad. Nietzsche, Guarulhos/Porto Seguro, v.39, n.1, p. 120-131, janeiro/abril, 2018. 
carne $^{12}$. Para além dessa explícita referência, creio que o termo pode ser utilizado, dada sua história no âmbito filosófico ${ }^{13}$, para indicar essa característica pela qual cultura é sempre "cultura de morte" e "devoradora de cadáveres".

No parágrafo 39 de $A$ gaia ciência se assinala de que maneira os juízos morais e estéticos respondem a alterações na physis e na alimentação: nesse sentido, pode-se compreender a cultura como esse processo de transformação de costumes (nesse caso, alimentícias) em ideais sublimes. Dessa maneira, a sarcofagia e a vivissecção podem ser pensadas como as bases de constituição da cultura (como enfrentamento à natureza). Ambas supõem crueldade no ferir a vida, seja para devorá-la, seja para observá-la. Mas a observação da vivissecção é também uma forma de devoração, porque se trata de roubar da vida seu segredo.

Quando Nietzsche caracteriza a civilização-domesticação [Civilisation-Zähmung], afirma que ela se constitui com "todo tipo de ferros e torturas para sustentar-se frente à atrocidade [Furchtbarkeit] e à natureza de animal predador" (Nachlass/FP 11 [53], 1887, KSA 13.72). Vale dizer, a cultura, que supostamente se constrói por oposição a uma interpretação da natureza como predação, ela mesma, sem dúvida, gera uma arquitetura de dispositivos predadores. A poetisa argentina Susana Thénon sugere que a "Filosofia significa "violação de um ser vivente"”'14, e Nietzsche indica que "a história da

12 Carta de abril 1869-dezembro 1874, p. 94.

13 A referência ao termo "sarkophagía" é sempre a Porfírio (De abstinentia, IV, 15); de fato, como mostra Marcel Detienne (Apolo con un cuchillo en la mano. Una aproximación experimental al politeísmo griego, trad. M. Llinares García. Madrid: Akal, 2001, pp. 70-71), a sarcofagia se inicia quando, diante das vítimas oferecidas aos deuses no holocausto, o sacerdote, incidentalmente, mancha os dedos de gordura, e essa gordura o atrai por seu sabor, dando início à dieta carnívora. Com isso, o sagrado e o fogo sacrificial se vinculam com a dieta humana. Os pitagóricos e órficos, antes de Porfírio, também devem ter utilizado o termo.

14 Cito parte de poema "Ova completa", do livro homônimo: "Filosofia significa 'violação de um ser vivente'./Vem do grego filoso, 'que corta muito',/e fia, $3^{\circ}$ pessoa do verbo fiar, que quer dizer/'confiar' e também 'dar sem cobrar ad referendum'./Exercem esta atividade os chamados Friends/ ou 'Irmandade dos Sorridentes",/os fiadores -desde logo-,/os que de veras têm a maçaneta e os que creem tê-la/

Cad. Nietzsche, Guarulhos/Porto Seguro, v.39, n.1, p. 120-131, janeiro/abril, 2018. 
Cragnolini, M. B.

filosofia é uma fúria secreta contra os pressupostos da vida, contra os sentimentos de valor da vida, contra tomar partido a favor da vida" (Nachlass/FP, 14 [134], 1888, KSA 13. 318) ${ }^{15}$. Dessa maneira, o modo de ser humano que se delineia a partir da filosofia (em especial, desde a época moderna) se constitui como oposição a uma suposta natureza interpretada de maneira predatória, porém reproduzindo essa crueldade nos dispositivos institucionais. A cultura se manifesta assim como vingança contra a vida que, em termos alimentícios, potencializa essa vingança na devoração do inimigo (o animal como oposição ao humano, que se constitui por uma "espiritualidade" que rechaça a "animalidade") $)^{16}$.

Frente a essa vingança contra a vida, a filosofia nietzschiana do amor nos pode permitir pensar outro vínculo com a comunidade do vivente. Sabemos que Nietzsche rechaça a caridade, tanto com respeito aos humanos, como com respeito aos animais ${ }^{17}$, e parte desse rechaço tem a ver com a questão do semelhante e do igual (a ideia de que devemos amar aquele que nos é igual ou de quem podemos nos aproximar por processos de assimilação a nosso modo de ser). $\mathrm{O}$ amor para Nietzsche é amor ao diferente, ao estranho, ao que não nivela na igualdade nem busca a "amorosa apropriação" do outro. Este amor ao estranho, que é aprendizagem, está exposto no

na descomunal mesquita de Oj-Alá". ["Filosofía significa "violación de un ser viviente'./Viene del griego filoso, 'que corta mucho',/y fía, $3^{\circ}$ persona del verbo fiar, que quiere decir/'confiar' y también 'dar sin cobrar ad referendum'./Ejercen esta actividad los llamados Friends/ o "Cofradía de los Sonrientes",/los fiadores -desde luego-,/los que de veras tienen la manija y los que creen tenerla/ en la descomunal mezquita de Oj-Alá".].

15 [Die Geschichte der Philosophie ist ein heimliches Wüthen gegen die Voraussetzungen des Lebens, gegen die Werthgefühle des Lebens, gegen das Parteinehmen zu Gunsten des Lebens].

16 J. Derrida desenvolveu a ideia de uma "guerra santa" contra o animal (2006). Remeto, para essa questão, a meu artigo citado na nota 9.

17 A "caridade aos animais", que na época de Nietzsche ocorria nas sociedades protetoras de animais, é rechaçada explicitamente: "Schopenhaueriana é a prédica de Wagner a respeito da caridade com os animais; no que Voltaire foi, como se sabe, um precursor de Schopenhauer na medida em que, como seus sucessores, soube converter em caridade para com os animais seu ódio a certas coisas e a certas pessoas". (FW/GC 99, KSA 3.453-457)

128 | Cad. Nietzsche, Guarulhos/Porto Seguro, v.39, n.1, p. 120-131, janeiro/abril, 2018. 
parágrafo 334 de $A$ gaia ciência, quando se fala de amor, assinalando que sempre somos recompensados em nossa doçura para com o estranho [Sanftmüthigkeit gegen das Fremde], que agradece nossa hospitalidade [Gastfreundschaft] (FW/GC 334, KSA 3.559).

Desse amor ao estranho é possível entender outra vinculação com o vivente na filosofia nietzschiana: se o nexo entre "história dos animais" e "filosofia da nutrição" potencializa o ódio contra a vida presente em nossos costumes morais-alimentícios, também permite pensar uma forma de amor ao vivente na comunidade de vida que somos. Frente à intenção apropriativa do segredo (do outro, da vida), a ciência jovial indica uma forma de amor hospitaleira para com a estranheza que o outro é. Essa estranheza que torna possível uma filosofia nietzschiana da alteridade, que leva em conta esse outro, mais outro que nenhum outro, que é o animal ${ }^{18}$.

18 Para o desenvolvimento dessa ideia, remeto a Mónica B. Cragnolini, 2012b. 
Cragnolini, M. B.

\begin{abstract}
In The Gay Science, Book I, Aphorism 7, which is entitled "Something for the industrious", Nietzsche points to a "work program" to the new gay science, programm that move away philosophy from usual places with which it is familiar. Likewise, in The Gay Science there are mentions about a "natural history of the animal" and, given the link between the birth of moral and our relation with animals (as observed in Human, all too Human II, 57), I consider that part of "this something" for the industrious in present times must be carried out regarding the animal issue. Then I will outline some propositions from Nietzschean philosophy in order to think this subject, mainly on the basis of the criticism and complaint of those humanists prejudices that continue to form a "naturalized" part of our link with animals.
\end{abstract}

Keywords: Nietzsche, Animal Studies, Sarcophagy, devouring.

\title{
Referências bibliográficas
}

CRAGNOLINI, Mónica B. "Ello piensa: la "otra" razón, la del cuerpo", en J. C. Cosentino-C. Escars (comp.). El problema económico. Yo-ello-super-yo-síntoma. Buenos Aires: Imago Mundi, 2005a, pp. 147-158.

CRAGNOLINI, Mónica B. "Nietzsche hospitalario y comunitario, una extraña apuesta. In: M. B. Cragnolini (comp.). Modos de lo extraño. Subjetividad y alteridad en el pensamiento postnietzscheano. Buenos Aires: Santiago Arcos, 2005b, pp. 11-27.

CRAGNOLINI, Mónica B. "Los animales de Zarathustra: Heidegger y Nietzsche en torno a la cuestión de lo viviente animal". In: Estudios Nietzsche, SEDEN, Málaga, N. 10 (2010), pp. 53-66.

CRAGNOLINI, Mónica B. "La ciencia jovial: un ejercicio del derroche frente a la 'guerra santa' contra el animal". In: Nómadas, Revista de la Universidad Central, Bogotá, Colombia, N. 37, octubre 2012(a), pp. 146-155.

CRAGNOLINI, Mónica B. "Los más extraños de los extranjeros: los animales". In: Actuel Marx/Intervenciones. Sgo de Chile, Universidad Arcis, N. 12, 1. semestre de 2012(b), pp. 139-145.

130 | Cad. Nietzsche, Guarulhos/Porto Seguro, v.39, n.1, p. 120-131, janeiro/abril, 2018. 
DERRIDA, J. L'animal que donc je suis. Paris: Galilée, 2006.

DETIENNE, Marcel. Apolo con un cuchillo en la mano. Una aproximación experimental al politeísmo griego, trad. M. Llinares García. Madrid: Akal, 2001.

NIETZSCHE, F. Sämtliche Werke. Kritische Studienausgabe (KSA: 15 vols.). Hrsg. von G. Colli und M. Montinari. Berlin/New York: de Gruyter, 1988.

NIETZSCHE, F. Correspondencia. Vol. I, abril 1869-diciembre 1874, trad. J. M. Romero Cuevas y M. Parmeggiani. Madrid: Trotta, 2007.

Artigo recebido para publicação em 20/08/2017 Artigo aceito para publicação em 21/11/2017 